TABLE IX - Estimate of excess deaths due to alcohol consumption in England and Wales by age group (based on Kaiser-Permanente study)

\begin{tabular}{lcc}
\hline Age range (years) & Estimate of excess deaths & $95 \%$ Confidence interval \\
\hline $15-34$ & 3716 & 3281 to 4525 \\
$35-64$ & 17284 & 15664 to 20193 \\
$65-74$ & 7178 & 6232 to 8680 \\
\hline Total population & 28178 & 25177 to 33398 \\
\hline
\end{tabular}

and Maynard was based on data from the early 1970s and on a select group of the population; "alcoholics" discharged from mental hospitals. Alcoholics are likely to contribute only a small proportion of the total excess mortality due to alcohol consumption. ${ }^{20}$ The Royal College of Physicians based its estimate on a Swedish population that is unlikely to be representative of the English and Welsh populations, and data were provided only for middle aged men. The estimate of the Royal College of General Practitioners was based on the total population aged over 15 , whereas most deaths occur in those aged over 75 , when there is great uncertainty over whether death is associated with alcohol consumption.

The estimate presented in this paper is based on methods previously applied to ascertain the association between death and cigarette smoking. ${ }^{11}$ Unfortunately there is no single basic study of the association of death with alcohol consumption so estimates were based on results from one British and four American studies.

The five studies used in my calculations have drawbacks. Firstly, four of the studies were carried out in the United States on populations differing in ethnic origin, social class, and employment state, all of which have independent effects on alcohol consumption and mortality. Data on mortality from these North American studies may not apply to populations in the United Kingdom. Secondly, a cohort phenomenon may limit the applicability of these studies. The risk related to alcohol consumption in populations derived 25 or so years ago may be different from that in current populations with the same alcohol consumption. Thirdly, four of the studies were studies of coronary heart disease; although they included an estimate of alcohol consumption, they were not designed to relate alcohol consumption to mortality. Finally, four of the five studies give little detail about risk for different age groups, providing data only for the range 35-64 years. Only the Kaiser-Permanente study provided adequate data for different age ranges.

An estimate of total excess deaths based on one study should increase the validity of this calculation. Based on the Kaiser-Permanente study the total excess mortality came to 28000 deaths. This is an estimate of the association between alcohol consumption and mortality, not between alcohol consumption and specific diseases. Further longitudinal studies are needed to investigate the association of alcohol consumption with morbidity and mortality.

\footnotetext{
1 Royal College of Physicians. A great and growing evil. London: Tavistock, 1987.

Royal College of Psychiatrists. Alcohol, our favourite drug. London: Tavistock, 1986:x.

Royal College of General Practitioners. Alcohol: a balanced view. London: RCGP, 1986:45.

McDonnell R, Maynard A. Estimation of life years lost from alcohol-related premature death. Alcohol Alcohol 1985;20:435-43.

Holtermann S, Burchell A. The costs of alcohol misuse. London: Department of Health and Social Security, 1981 .

6 Wilkins R. The hidden alcoholic in general practice. London: Elek Science, 1974.

7 Donnan SPB, Haskey J. Alcoholism and cirrhosis of the liver. Population Trends 1977;7:18-24.

8 Schmidt $W$, de Lint J. Estimating the prevalence of alcoholism from alcohol consumption and mortality data. Qf Stud Alcohol 1970;31:957-64

9 Adelstein A, White G. Alcoholism and morbidity. Population Trends 1976;6: 7-13.

10 Petersson B, Trell E, Henningsen N-C, Hood B. Risk factors for premature death in middle aged men. $\mathrm{Br} M e d \mathcal{F}$ 1984;288:1264-8.

11 Royal College of Physicians. Smoking and health now. London: Pitman Medical, 1971.

12 Central Statistical Office. Social trends. London: HMSO, 1987;16:19-21.

13 Wilson P. Drinking in England and Wales. London: HMSO, 1980:10.

14 Office of Population Censuses and Surveys. Deaths by cause, 1984. OPCS Monitor 1985: No 3 . (DH2 85/3.)

15 Blackwelder WC, Yano K, Rhodes GG, Kogan A, Gordon T, Palesch Y. Alcohol and mortality: the Honolulu heart study. Am f Med 1980;60:164-9. 16 Marmot MG, Rose G, Shipley NJ, Thomas BJ. Alcohol and mortality: a U-shaped curve. Lancet 1981;i:580-2.

17 Klatsky AL, Friedman GD, Siegelaub AB. Alcohol and mortality: a ten-year Kaiser-Permanente experience. Ann Intern Med 1981;95:139-45.

18 Dyer AR, Stamler J, Paul O, et al. Alcohol consumption and 17-year mortality in the Chicago Western Electric Company study. Prev Med 1980;9:78-90. 9 Gordon T, Kannel WB. Drinking and mortality. Am $\mathcal{F}$ Epidemiol 1984;120: 97-107.

20 Kreitman N. Alcohol consumption and the preventive paradox. $\mathrm{Br} \mathcal{F}$ Addict 1986;81:353-63.
}

(Accepted 3 fune 1988)

\title{
Postmarketing surveillance of enalapril. I: Results of prescription-event monitoring
}

Drug Safety Research Unit, Botley, Southampton William H W Inman, FRCP, director and professor of pharmacoepidemiology Nigel S B Rawson, PHD, principal research officer Lynda V Wilton, PHD, senior research officer

Gillian L Pearce, BSC, senior technical officer

\section{Department of Clinical} Pharmacology, Royal Postgraduate Medical School, London W12 0NN Christopher J Speirs, MRCP, lecturer in clinical toxicology

Correspondence and requests for reprints to Professor W H W Inman, Drug Safety Research Unit, North Croft House,

Winchester Road, Botley, Southampton SO3 2BX.

\section{William H W Inman, Nigel S B Rawson, Lynda V Wilton, Gillian L Pearce, Christopher J Speirs}

\section{Abstract}

To identify and measure the incidence of adverse effects of the angiotensin converting enzyme inhibitor enalapril 13713 patients were studied for one year by prescription-event monitoring. Precise information about the duration of treatment was available for 12543 patients. The frequency of many events was calculated, including dizziness $(483$ patients; $3.9 \%)$, persistent dry cough $(360 ; 2.9 \%)$, headache $(310 ; 2.5 \%)$ hypotension $(218 ; 1.7 \%)$, and syncope $(155 ; 1 \cdot 2 \%)$. Less common reactions included angioedema, urticaria, and muscle cramps. Altogether $1098(8 \%)$ patients died and the notes of 913 of them $(83 \%)$ were obtained for detailed scrutiny. With the exception of a few patients with renal failure who deteriorated during treatment (reported on separately), no death was attributed to enalapril. Enalapril was considered to be effective, even in patients with advanced cardiac failure.

These results for enalapril are reassuring and provide further evidence of the value of prescriptionevent monitoring.

\section{Introduction}

The angiotensin-converting enzyme inhibitor enalapril maleate was first marketed in general practice in the United Kingdom in April 1985. Arrangements were made immediately to conduct postmarketing surveillance by prescription-event monitoring, which has been developed by the Drug Safety Research Unit. The purpose of prescription-event monitoring is to identify and measure adverse effects of new drugs soon after their introduction into general practice.

\section{Patients and methods}

The method has been described elsewhere. ' Briefly, prescription-event monitoring uses copies of NHS prescriptions as a means of identifying a patient, a 
doctor, and exposure to a drug. After one year each doctor is asked to complete a simple questionnaire describing any "event" that might have been recorded since the first prescription for the individual patient. An event is defined as a diagnosis, sign or symptom, accident, operation, change of treatment, or any other incident that the doctor had considered to be important enough to record in the patient's notes.

Prescription forms for enalapril written by general practitioners in England between April and December 1985 were photocopied by the Prescription Pricing Authority and posted to the Drug Safety Research Unit. Information from forms on which the name and at least part of the address of the patient could be read was entered into the unit's computer. Questionnaires (green forms) printed by the computer were posted to the prescriber on the anniversary of the first prescription for each patient. This allowed the recording of events experienced over 12 months, irrespective of whether the patient had continued to use enalapril throughout.

The manufacturer was already conducting a large postmarketing study of enalapril, in which general practitioners had recruited patients with mild to moderate hypertension. ${ }^{2}$ Hence to avoid possible bias each prescription received by the Drug Safety Research Unit was checked against a list of some 2450 doctors supplied by the company so that the same doctor would not be invited to participate in both studies. Roughly half the patients had received prescriptions from doctors who were participating in the company study. Over 120000 prescriptions needed to be processed in order to identify 22417 patients.

The data presented below are derived from the 15169 green forms that were returned. Of these, 1456 $(9 \cdot 6 \%)$ provided no information, usually because the patient was no longer registered with the practice. Of the remaining 13713 forms, $12543(83 \%$ of all forms returned) gave precise information about the duration of treatment. This number was used to calculate the rates of events occurring during the 12 months of observation. Events recorded during the 13th and subsequent months were not included in the calculation of rates of events during or after treatment.

A total of 1109 patients were reported to have died, but subsequent follow up gave the true number as 1098. Because the patients' notes had usually been returned to the family practitioner committee information about the diagnosis or date of death or its relation to treatment with enalapril was deficient in a

TABLE I-Numbers of patients experiencing events of special interest

\begin{tabular}{|c|c|c|c|c|}
\hline \multirow[b]{2}{*}{ Selected individual events } & \multirow{2}{*}{$\begin{array}{l}\text { No during } 12 \text { months } \\
\text { of observation }\end{array}$} & \multirow{2}{*}{$\begin{array}{c}\% \text { Of patients } \\
(n=12543)\end{array}$} & \multicolumn{2}{|c|}{$\begin{array}{l}\text { No of events and excess rate } / 1000 \\
\text { patients during first month ( } 99 \% \\
\text { confidence interval) }\end{array}$} \\
\hline & & & No & Excess rate \\
\hline \multicolumn{5}{|l|}{ Skin: } \\
\hline Angioedema & 27 & $0 \cdot 2$ & 6 & $0 \cdot 3$ \\
\hline Photosensitivity & 15 & $0 \cdot 1$ & 1 & $0 \cdot 0$ \\
\hline Urticaria & 32 & $0 \cdot 3$ & 5 & $0 \cdot 2$ \\
\hline Other acute events & 298 & $2 \cdot 4$ & 36 & 0.9 \\
\hline \multicolumn{5}{|c|}{ Central nervous system and eye: } \\
\hline Syncope & 155 & $1 \cdot 2$ & 29 & $1.4(0.3$ to 2.5$)$ \\
\hline Dizziness & 483 & 3.9 & 152 & $9 \cdot 7(7 \cdot 2$ to $12 \cdot 3)$ \\
\hline Headache & 310 & $2 \cdot 5$ & 94 & $5.9(3.9$ to 7.4$)$ \\
\hline Convulsions & 22 & $0 \cdot 2$ & 1 & -0.1 \\
\hline Paraesthesia & 126 & 1.0 & 29 & $1.6(0.5$ to 2.7$)$ \\
\hline Taste disturbance & 25 & $0 \cdot 2$ & 2 & 0.0 \\
\hline Conjunctivitis & 67 & 0.5 & 6 & 0.0 \\
\hline \multicolumn{5}{|l|}{ Cardiovascular: } \\
\hline Hypotension & 218 & $1 \cdot 7$ & 71 & $4.6(2 \cdot 8$ to $6 \cdot 3)$ \\
\hline Tachycardia & 194 & 1.5 & 69 & $4.6(2.9$ to $6 \cdot 3)$ \\
\hline \multicolumn{5}{|l|}{ Respiratory: } \\
\hline Cough & 360 & $2 \cdot 9$ & 54 & $2.0(0.5$ to 3.6$)$ \\
\hline \multicolumn{5}{|l|}{ Renal: } \\
\hline Renal failure & 82 & 0.7 & 9 & $0 \cdot 2$ \\
\hline \multicolumn{5}{|l|}{ Miscellaneous: } \\
\hline Cramp & 96 & 0.8 & 19 & $0.9(0.0$ to 1.9$)$ \\
\hline Diarrhoea & 236 & 1.9 & 63 & $3 \cdot 7(2 \cdot 1$ to $5 \cdot 4)$ \\
\hline Nausea and vomiting & 326 & $2 \cdot 6$ & 97 & $6 \cdot 1(4 \cdot 0$ to $8 \cdot 1)$ \\
\hline
\end{tabular}

total of $809(74 \%)$ of the deaths. An attempt was therefore made to supplement the information on the green forms by following up all deaths. General practitioners were asked if they had any objection to releasing the notes. In some cases these had already been destroyed and in others they could not be located. General practice notes were eventually obtained for $913(83 \%)$ of the 1098 patients.

The data were analysed in various ways. Changes in the frequency of events were studied month by month in order to detect important trends. If, for example, the events were particularly numerous in the first month and the rate then fell we considered the possibility that the early "cluster" might be related to treatment. Events that were unrelated to treatment should have been fairly evenly distributed throughout the 12 months of observation.

\section{Results}

Of patients whose age and sex were recorded, just over half were female (average age 63 years; range 12-98). The average age of male patients was 59 years (range 16-99). In cases in which the general practitioner had answered the question about efficacy enalapril was thought to have been effective in $83 \%$ of patients.

A total of 19504 events were recorded on the 13713 forms. Of these events, 13151 occurred during treatment and 2128 after treatment among the 12543 patients for whom the precise dates of treatment were recorded. A further 2079 events occurred 13 or more months after the first prescription, and there was no precise record of the dates of prescription or of the date of the event for the remaining 2146 events.

Table I shows the proportions of patients experiencing certain events of special interest and the numbers of these events during the first month. Table I also gives an estimate of the excess rate per 1000 patients during the first month (when most acute adverse drug effects would be expected to occur) and the $99 \%$ confidence intervals for these estimates, assuming a Poisson model.

\section{SKIN EVENTS}

Three hundred seventy two skin events during the 12 months were of acute onset. Only five doctors informed us that these had been reported to the Committee on Safety of Medicines as suspected adverse reactions. There were 29 cases of facial oedema or angioedema $(0.2 \%)$, two of which occurred more than one year after starting enalapril. Only 10 led to stopping treatment. Six cases occurred during the first month and the remainder were scattered over the rest of the year. No patient became seriously ill. There were 15 reports of photosensitivity $(0 \cdot 1 \%)$. Thirty two patients $(0 \cdot 3 \%)$ developed urticaria, which necessitated withdrawing the drug in five cases. Six other cases of urticaria were attributed to drugs other than enalapril. The excess of acute skin events during the first month was only $1 \cdot 4 / 1000$ patients.

\section{CENTRAL NERVOUS SYSTEM EVENTS}

One hundred fifty five patients $(1 \cdot 2 \%)$ experienced syncope and $483(3.9 \%)$ complained of dizziness, both of which were sometimes associated with hypotension. A total of 310 patients $(2 \cdot 5 \%)$ complained of headache.

Twenty two records of convulsions $(0 \cdot 2 \%)$ were followed up. One was probably a syncopal attack in a patient fitted with a pacemaker. Eight patients were known epileptics, in whom the fits were considered to be unrelated to enalapril. Seven others were considered to have been caused by brain damage resulting from cerebrovascular accidents. One patient with cerebrovascular disease had a fit when her blood pressure 
reached $210 / 115 \mathrm{~mm} \mathrm{Hg}$. One was thought to have had a convulsion as a result of severe hypokalaemia associated with an adrenal tumour, which was removed successfully. One man had a convulsion which was thought to have been related to sleep deprivation after a long journey by air. In three cases the fit occurred after enalapril had been stopped. No cause for the convulsions could be identified in three cases.

One hundred twenty six reports of paraesthesia $(1.0 \%)$ in limbs or face were associated in many cases with orthopaedic conditions such as cervical spondylosis or carpal tunnel syndrome or with cerebrovascular disturbances such as transient ischaemic attacks. Twenty five patients $(0 \cdot 2 \%)$ complained of an alteration of taste (dysgeusia), sometimes described as "sweet" or "metallic," which disappeared when the drug was stopped. There seems to have been a definite association with enalapril in most of these patients.

\section{OPHTHALMIC EVENTS}

Sixty seven patients $(0.5 \%)$ developed conjunctivitis, though none stopped treatment because of it. The cases were scattered fairly uniformly throughout the 12 months of observation. Seventeen were considered to have an unlikely relation to enalapril because the condition was either unilateral (15) or purulent (one) or had originally developed as a result of practolol (one). In the remainder enalapril cannot be ruled out but there seems to have been no clear cut temporal relation.

\section{CARDIOVASCULAR EVENTS}

Most cardiovascular events were related to the indications for which enalapril had been prescribedusually hypertension and heart failure-but two events were associated with treatment. Tachycardia (palpitation) was recorded in 194 patients $(1 \cdot 5 \%)$. There were 218 reports of hypotension $(1 \cdot 7 \%), 71$ cases $(33 \%)$ occurring during the first month of treatment. Forty four cases $(20 \%)$ occurred at doses of 2.5 or $5 \mathrm{mg}$, $119(55 \%)$ at $10 \mathrm{mg}$, and $55(25 \%)$ at doses of $15-40 \mathrm{mg}$ daily. One hundred and twenty one patients stopped treatment because of it, 36 continued at a reduced dose, and 61 continued at the same dose. Ninety two reports stated that the hypotension was postural. Elderly patients in heart failure were particularly likely to develop hypotension after small doses.

\section{RESPIRATORY EVENTS}

A total of 360 patients complained of cough $(2.9 \%)$, usually described as "dry" or "tickling" and unproductive. Onset was uniformly distributed throughout the year, persisting during treatment and disappearing after enalapril was stopped.

\section{RENAL EVENTS}

Eighty two cases of renal failure were recorded

TABLE II-Numbers of deaths and average monthly death rate

\begin{tabular}{|c|c|c|c|c|c|c|}
\hline \multirow[b]{3}{*}{ Cause of death } & \multirow{3}{*}{$\begin{array}{l}\text { Total } \\
\text { No of } \\
\text { deaths }\end{array}$} & \multicolumn{4}{|c|}{ No of deaths/1000 patients/month } & \multirow{3}{*}{$\begin{array}{l}\text { Deaths occurring } \\
\text { after more than one } \\
\text { year or in which } \\
\text { relation to treat- } \\
\text { ment was uncertain }\end{array}$} \\
\hline & & \multicolumn{2}{|c|}{ During treatment } & \multicolumn{2}{|c|}{ After treatment } & \\
\hline & & No & Rate & No & Rate & \\
\hline Congestive cardiac failure & 224 & 109 & $0 \cdot 9$ & 60 & $1 \cdot 7$ & 55 \\
\hline Left ventricular failure & 43 & 20 & $0 \cdot 2$ & 17 & 0.5 & 6 \\
\hline Myocardial infarction & 252 & 125 & $1 \cdot 1$ & 50 & 1.5 & 77 \\
\hline Cerebrovascular accident & 66 & 28 & $0 \cdot 2$ & 12 & 0.3 & 26 \\
\hline Other cardiovascular causes & 166 & 73 & 0.6 & 36 & $1 \cdot 0$ & 57 \\
\hline Respiratory disorders & 47 & 16 & $0 \cdot 1$ & 14 & 0.4 & 17 \\
\hline Renal disorders & 75 & 39 & 0.3 & 18 & 0.5 & 18 \\
\hline Cancer & 61 & 14 & $0 \cdot 1$ & 22 & 0.6 & 25 \\
\hline Other causes & 41 & 10 & $0 \cdot 1$ & 14 & 0.4 & 17 \\
\hline All deaths & 975 & 434 & $3 \cdot 7$ & 243 & $7 \cdot 1$ & 298 \\
\hline
\end{tabular}

^Denominators used to calculate rates: 116100 patient months during treatment; 34400 patient months after treatment.
$(0 \cdot 7 \%)$. An investigation of deaths associated with renal failure is presented in our accompanying paper. ${ }^{3}$

\section{MISCELLANEOUS EVENTS}

There were 236 records of diarrhoea $(1.9 \%)$ and 326 of nausea and vomiting $(2 \cdot 6 \%)$. Ninety six patients $(0.8 \%)$ complained of cramp.

\section{DEATHS}

We established the true overall mortality in the series as 1098 deaths $(8 \%)$. The cause of 123 deaths was not ascertained because the doctor did not reply (16), the family practitioner committee did not reply (37) or could not trace the records (26), or the records, when obtained, did not include the information required (42). Two patients died abroad. Table II shows the causes of death and relation to treatment in the remaining 975 patients. The cause of death was confirmed from notes obtained from the family practitioner committee in 913 cases.

Four hundred thirty four deaths $(45 \%)$ occurred during treatment and $243(25 \%)$ after it had been stopped. In a further 298 users (31\%) either death occurred after the one year period of observation or there was no record of whether the patient was still taking enalapril immediately before death. The death rates during and after treatment averaged 3.7 and $7 \cdot 1$ / 1000 patients a month respectively.

Cardiovascular deaths predominated, and the only 10 deaths that might have been attributable to enalapril were among the 75 deaths from renal disorders (see accompanying paper).

\section{Discussion}

Since 1982 prescription-event monitoring has been the second national scheme for postmarketing surveillance, complementary to the Committee on Safety of Medicines' yellow card system. There have been many variations and improvements in methodology as the scheme has developed. This is the first occasion that a full month by month review of events in all patients has been possible. We believe that the results of this study will be useful for direct comparison with similar studies of other angiotensin converting enzyme inhibitors which will be marketed in the future and with findings in patients suffering from hypertension or cardiac failure treated with other drugs.

The analysis of estimates of the excess risk shown in table I refers only to acute drug induced events with onset mostly during the first month of treatment. For effects that were slow to develop, such as dry, irritating cough, or which persisted throughout treatment there was little or no excess during the first month, and the frequency of such events can be measured only by comparing the average rates during treatment with the average rate in patients who had stopped treatment. Other events such as photosensitivity, convulsions, and conjunctivitis, on the other hand, were fairly uniformly distributed throughout the period of observation irrespective of whether patients continued with treatment.

Some other deficiencies remain to be overcome. Many general practitioners assumed that because there were only two main indications for enalapril there was no need to record these on the green form. Another problem arose when patients were admitted to rest homes or terminal care units. This frequently made it difficult or impossible to ascertain whether the patient had continued with treatment after admission or what events immediately preceded death.

Prescription-event monitoring had not been developed when captopril was first marketed in the United Kingdom and it is difficult to make precise 
comparisons. Adverse effects that have been observed during treatment with captopril and other angiotensin converting enzyme inhibitors include haematological and renal toxicity, rash, dysgeusia, gastrointestinal problems, cough, and pharmacological effects such as hypotension and related events-for example, syncope and dizziness. ${ }^{4}$ This study of enalapril found a similar range of adverse effects, but the rates were generally lower than with captopril.

Hypotension was reported in 218 patients $(1 \cdot 7 \%)$; syncope and dizziness, which may have been related to the same problem, were reported in $1.2 \%$ and $3.9 \%$ of patients respectively. These rates were similar to those recorded in controlled clinical studies. ${ }^{5}$ Though not always stated, it was clear from the dates of the events that hypotension, dizziness, and headache were a fairly frequent reason for stopping treatment.

Neutropenia with captopril has been reported in between one and three per 1000 patients, ${ }^{67}$ usually those with renal impairment. This has not been reported with enalapril. ${ }^{258}$ In our study only two cases of leucopenia were recorded among more than 12000 patients and there was no evidence that they were caused by the drug.

In the manufacturer's study of a highly selected group of 11710 patients with mild to moderate hypertension treated with enalapril for six weeks there were 10 deaths (equivalent to a rate of $0.7 \%$ a year) and no case of renal failure. In our series there were 1098 deaths $(8 \cdot 8 \%$ a year), 75 of them from renal failure. There is no selection in prescription-event monitoring, which reflects the "real life" conditions of drug use in general practice. Because of the large difference in results between the two studies and the possibility that some patients' renal function might deteriorate as a result of using the drug we decided to use the database established by prescription-event monitoring for an important investigation launched in February $1987 .{ }^{3}$

Though some of the less serious adverse effects may have been underestimated because they were not noted in the records, prescription-event monitoring identified persistent dry cough, dysgeusia, and headache as probable side effects. Care is required in the interpretation of disorders such as headache. An apparent excess during the first month of treatment may merely reflect a beneficial effect of the drug in reducing the frequency of headache in subsequent months. Skin reactions are comparatively common with captopril, occurring in $4-7 \%$ of all patients. ${ }^{4}$ Our results suggest that enalapril induced skin reactions are less common, probably affecting only between one and two in every 1000.

Dry, unproductive cough was reported by 360 patients $(2 \cdot 9 \%)$. This rate was similar to that reported by us in a preliminary note ${ }^{9}$ and by the New Zealand Intensive Medicines Monitoring Programme. ${ }^{10}$ Though most effects attributable to enalapril occurred early in treatment, new cases of dry cough occurred throughout the year of the study. The rate of new cases was $0.4 \%$ during the first month and averaged $0.3 \%$ during each subsequent month, the cough disappearing after stopping enalapril.

Dysgeusia is thought to occur in $1 \cdot 4-2 \cdot 1 \%$ of patients taking captopril. ${ }^{4}$ Only 25 patients $(0.2 \%)$ complained of this effect during prescription-event monitoring, though a definite association with enalapril was apparent in most of them.

We believe that the incidence of side effects with enalapril is acceptably low and that the drug may have some advantage over captopril in this respect. Though prescription-event monitoring is not designed primarily to assess efficacy, it was plainly evident that enalapril had considerably improved the quality of life and possibly prolonged it in many seriously ill patients.

We thank the Prescription Pricing Authority for supplying copies of prescriptions for enalapril and the more than 8000 general practitioners who took part in the study. We also thank some 20 manufacturers, including Merck Sharp and Dohme, and the Department of Health and Social Security for the unconditional support which makes prescriptionevent monitoring possible. We thank Professor D J Finney for statistical advice. Finally, we thank those family practitioner committees who facilitate follow up of patients who have died, colleagues at the Drug Safety Research Unit who prepared the data, and Mrs Barbara Hunt for preparing the manuscript.

1 Inman WHW, Rawson NSB, Wilton LV. Prescription-event monitoring. In Inman WHW, ed. Monitoring for drug safety. 2nd ed. Lancaster: MTP Press, 1986:213-35.

2 Cooper WD, Sheldon D, Brown D, Kimber GR, Isitt VL, Currie WJC. Postmarketing surveillance of enalapril: experience in 11710 hypertensive patients in general practice. $7 R$ Coll Gen Pract 1987:37:346-9.

3 Speirs CJ, Dollery CT, Inman WHW, Rawson NSB, Witton LV Postmarketing surveillance of enalapril. II: Investigation of the role of enalapril in deaths with renal failure. $\mathrm{Br}$ Med $\mathcal{F}$ 1988;297:830-2.

4 DiBianco R. Adverse reactions with angiotensin converting enzyme (ACE) inhibitors. Medical Toxicology 1986;1:122-41.

5 Irvin JD, Viau JM. Safety profiles of the angiotensin converting enzyme inhibitors captopril and enalapril. Am f Med 1986;81(suppl 4C):46-50.

6 Frohlich ED, Cooper RA, Lewis EJ. Review of the overall experience of captopril in hypertension. Arch Intern Med 1984;144:1441-4.

7 Jenkins AC, Dreslinski GR, Tadros SS, Groel JT, Fand R, Herczcg SA. Captopril in hypertension: seven years later. $\mathcal{f}$ Cardiovasc Pharmacol 1985; 7(suppl 1):96-101.

8 Edwards IR, Coulter DM, Beasley DMG, MacIntosh D. Captopril: 4 years of postmarketing surveillance of all patients in New Zealand. $\mathrm{Br} \mathbf{f}$ Clin Pharmacol 1987;23:529-36.

9 Inman WHW. Enalapril-induced cough. Lancet 1986;ii:1218.

10 Coulter DM, Edwards IR. Cough associated with captopril and enalapril. BrMed F 1987;294:1521-3.

(Accepted 10 fune 1988)

\section{ONE HUNDRED YEARS AGO}

IN teaching science, a double aim is sought-to impart knowledge, and to give mental training; both objects are of great importance to the student. It is frequently a subject of regret to see how soon physiology, anatomy, and chemistry are forgotten by the student who has passed his examinations in those subjects, although he may have worked industriously at them in his earlier years. We cannot but think that this is in part due to failure in training the student to think and argue for himself about what he sees in the laboratory and the class-room. Observing facts does not necessarily imply thinking about them; to make logical comparisons and analogies between objects seen, to trace out under wise supervision the sequences.of events as demonstrated by what is seen does compel thinking. Questions asked as to the action of different groups of muscles, and as to the muscles, the nerves, and the nerve centres which produce certain visible movements; such methods tend to produce efficient thinking, and add a practical interest to physiological and anatomical studies. In the hospital some students are too apt to be satisfied with detecting physical signs; a systolic apical bruit is detected over the heart, and the hasty inference is drawn that the mitral valve is diseased, and that this constitutes a diagnosis justifying at once the prescription of digitalis and iron. The bruit is a very important piece of initial evidence, and suggests the hypothesis of possible mitral disease, and the necessity of looking to all the physical conditions of the heart and the circulation in the pulmonary and systemic systems, as well as in the various viscera. A successful observation should stimulate thought, and lead to further observation. A patient complains of pain in the chest; on listening no friction is heard, and no abnormal dullness is found; the hasty conclusion may be drawn that no pleurisy is present, the student neglecting to take the temperature and to look for all the signs of pleurisy. Such habits of want of thoughtfulness lead to bad practice. Every observation should be followed by thought as to its significance and its relations to our knowledge; such mental habits may be inculcated in teaching science. It is not only in clinical work that the need for correct thinking is seen; in the examination room we have frequently seen candidates fail to answer simple questions, not necessarily through ignorance, but because they were unpractised in continuous and regular habits of thought.

(British Medical Fournal 1988;i:1018.) 